\title{
Políticas contra o racismo e opinião pública: comparações entre Brasil e Estados Unidos
}

\begin{tabular}{c}
\hline Edward Telles \\
Universidade de California, Los Angeles (UCLA) \\
Stan Bailey \\
Universidade de California, Los Angeles (UCLA) ${ }^{1}$ \\
\hline \hline
\end{tabular}

\section{Políticas contra o racismo e opinião pública: comparações entre Brasil e Estados Unidos}

Este artigo examina o apoio ao princípio de intervenção do governo na promoção dos negros através de duas políticas específicas:as quotas para negros nas universidades e as quotas para negros nos bons empregos. A análise está baseada na Pesquisa sobre Atitudes Raciais, realizada no Estado do Rio de Janeiro em 2000, dirigida por CEAP e aplicada pelo DATAUFF, e faz uma comparação com pesquisas realizadas nos Estados Unidos. Os resultados gerais mostram, como era esperado, a maioria de negros com tendência a apoiar políticas compensatórias para negros, e uma tendência a discordar entre os brancos. No Brasil, há uma resistência da elite branca em apoiar políticas compensatórias, mas há uma conjuntura favorável a uma discussão sobre estas políticas.

Palavras-chave: racismo, negros, ações afirmativas, Brasil

\section{Anti-racism policies and public opinion: comparisons between Brazil and United States}

This article studies the support to the principle of the public intervention for affirmative actions directed to black people through two public policies: quotas in universities, and quotas in good jobs. This study is based on the Survey on Racial Attitudes, conducted in Rio de Janeiro in 2000 by CEAP and DATAUFF, and it compares the Brazilian research data to American data. General results show, as it was expected, a major trend among black people to support the compensatory policies, and a trend against it among white people. In Brazil the 'white elite' resists to support compensatory policies, although there is a positive conjuncture to discuss them.

Key words: racism, negro, afirmative actions, Brazil

\footnotetext{
1 Telles é Professor na UCLA e Bailey é aluno de pós-graduação da mesma uiversidade. Durante o periodo da pesquisa, o primeiro autor era Assessor de Programas da Fundação Ford no Rio de Janeiro, licenciado da Universidade, o segundo autor também residia no Rio e pesquisava atitudes raciais para sua tese de doutorado.
} 
As políticas anti-racistas representam possíveis soluções para o combate ao racismo e a desigualdade racial. No Brasil, onde tais políticas anti-racistas não existem, a opinião pública pode ajudar a mostrar o quanto é desejável a sua implementação. O formato dessas políticas pode variar da criação de quotas para promoção dos negros, até medidas mais universalistas de redução do número de pobres, dos quais a maioria é composta de negros (pretos e pardos) no Brasil. Neste artigo, examinamos o grau de apoio ao princípio de intervenção do governo na promoção do negro através de duas políticas específicas, e que têm sido objeto de recentes discussões: trata-se da discussão sobre quotas para negros nas universidades e de quotas para negros nos bons empregos.

Nossa análise é baseada na Pesquisa sobre Atitudes Raciais, realizada no Estado do Rio de Janeiro, dirigida pelo CEAP e aplicada pelo DATAUFF. Participamos do desenho desta pesquisa junto com pesquisadores do CEAP, e este representa o primeiro "survey" por amostragem probabilística por domicílios desta natureza no país. Este método é reconhecido por organizações de pesquisa, inclusive pelo IBGE, como a única maneira de assegurar uma representação fiel da população pesquisada, neste caso, o Estado do Rio de Janeiro. Os resultados para o Rio de Janeiro não devem ser generalizados para todo o país; no entanto, em uma pesquisa nacional sobre atitudes raciais realizada pelo Instituto DataFolha em 1995

baseada numa amostra de quotas na rua, encontrou-se poucas diferenças por região nas várias questões aplicadas.

A pesquisa que utilizamos foi longamente pré-testada com objetivo de eliminar ambigüidades nos enunciados das perguntas e para ser entendida por todos os setores da população. As perguntas foram elaboradas segundo critérios rigorosos e com a preocupação da comparabilidade com outros contextos, sem perder as especifidades brasileiras. Algumas delas foram desenhadas especificamente para comparar com os Estados Unidos, que conta com uma longa tradição de pesquisas deste tipo. Assim, nossa preocupação principal foi elaborar perguntas que tinham sentido para o caso brasileiro, mas sempre que possível, foram incorporadas questões já aplicadas nos Estados Unidos. Para este artigo selecionamos algumas das perguntas que mais se assemelham e enfocamos a comparação dos seus resultados para os dois países.

A comparação desses dois contextos é algo complexo e deve ser cuidadosa. Entre as dificuldades, deve-se ter presentes as diferenças para definir raça ou cor, as várias maneiras e filtros pelos quais passa a problemática racial, assim como os problemas de tradução linguística. Em particular, no caso de políticas anti-racistas, trata-se da comparação entre um contexto com quase nenhuma história de políticas específicas para negros, como é o Brasil, com um outro de longa tradição de políticas púbicas para promoção dos negros e outros grupos em desvantagem. 
Cabe lembrar que os Estados Unidos têm 35 anos de programas centrais na política nacional, desenvolvidos para superar o racismo e promover negros, mulheres e outras minorias, e que conformam o reconhecimento popular dessas ações (Omi and Winant 1994). Como já salientamos, nunca foram aplicadas perguntas exatamente iguais entre os países, mas encontramos três que são bastante similares e permitem-nos algumas comparações entre os países.

Neste artigo, sustentamos a hipótese de que há diferenças de opiniões entre brancos e negros brasileiros sobre as ações para o combate ao racismo. Esta seria uma área de diferenças raciais esperada, em vista dos benefícios potenciais para o grupo negro e a possível percepção de perdas para os brancos, tanto no Brasil como nos Estados Unidos.

Antes de analisar essas perguntas, queremos deixar claras as classificações raciais com que trabalhamos. No caso dos Estados Unidos, examinamos só as opiniões de brancos e negros, e com isto eliminamos pessoas que se autoidentificam em outras categorias como latinos, asiáticos ou indígenas. Para o Rio de Janeiro, a auto-identificação das pessoas inclui as categorias branco, amarelo, pardo, indígena e preto, tal como aparece nos censos populacionais oficiais. Neste estudo, juntamos pessoas que se auto-identificaram como pretos e pardos para formar a categoria negros. Os que se identificaram como amarelos e indígenas foram excluídos da análise. Como resultado final, trabalhamos com uma população composta de $53 \%$ de negros e $47 \%$ de brancos.

Nossa análise inicia com a pergunta a respeito da existência de ancestrais negros, devido a considerarmos que os resultados poderiam indicar diferenças importantes quanto a identidades raciais. A pergunta feita a todas as pessoas entrevistadas, exceto aos que se auto-identificaram como pretos, foi: "você tem algum antepassado negro ou Africano?". A pesquisa também perguntou aos nãoindígenas, "você tem algum antepassado indígena", e finalmente, aos não-brancos, "você tem algum antepassado branco?". Os resultados apresentados na Tabela I são surpreendentes, pois mostram que $37 \%$ dos brancos brasileiros declararam ter algum antepassado negro. Levando-se em conta um certo estigma associado a ter antepassados negros (Twine 1998), esta porcentagem poderia ser ainda maior.

Nos Estados Unidos, por definição das leis segregacionistas que vigoravam até há 35 anos atrás, quem é branco não tem "nenhuma gota de sangue negra". Portanto, os resultados brasileiros sugerem uma grande diferença com relação aos Estados Unidos, onde a divisão entre negros e brancos tem pouca ambigüidade. Não conhecemos dados sobre a pergunta similar para os Estados Unidos, talvez porque sendo seu resultado considerado óbvio, a pergunta não se aplicasse. Os resultados para o Rio de Janeiro confirmam um recente estudo genético da Universidade Federal de Minas Gerais (Pena e outros:2000) que mostra que nas 
veias de muitos brasileiros brancos corre sangue africano e conclui que as diferenças entre brancos e não-brancos não são nítidas.

No caso da população que classificamos como negra, $80 \%$ dos pardos e $59 \%$ dos pretos dizem ter antepassados brancos. Não sabemos qual seria a resposta para negros norte-americanos, já que isso nunca foi perguntado, no entanto, poderia se esperar que uma alta porcentagem dessa população declararia ter antepassados brancos, pois tradicionalmente todas as pessoas com uma gota de sangue negro são colocadas nesta categoria, mesmo se seus antepassados na maioria forem brancos.

Para analisar as atitudes em relação às políticas anti-racistas escolhemos três perguntas. A primeira é sobre se o governo deveria ter obrigação especial para ajudar aos negros; a segunda é se deveriam ter quotas para a entrada de negros nas universidades e a terceira é sobre quotas nos empregos de boa remuneração. A primeira é quase igual para o Rio de Janeiro e os Estados Unidos, enquanto as últimas duas foram distintas. Todas as respostas revelam diferenças entre os dois países.

A primeira pergunta foi "Algumas pessoas acham que os negros no Brasil [ou Estados Unidos] têm sido discriminados por tanto tempo que o Governo tem uma obrigação especial de ajudá-los a melhorar suas condições de vida. Outras pessoas acham que o Governo não deve dar aos negros um tratamento especial ou diferente do restante da população. O Sr(a). acha que..." As possíveis respostas variaram entre os países. Enquanto no Brasil as respostas poderiam ser apenas duas, "o Governo tem uma obrigação especial com os negros", ou, "o Governo não deve dar aos negros um tratamento especial ou diferente do restante da população", nos Estados Unidos se permitiu uma resposta intermediária para quem concorda com as duas posições.

TABELA 1

Porcentagem das pessoas que se auto-identificam como branco, pardo e preto* que responderam ter antepassados brancos, índios ou negros. (Estado do Rio de Janeiro, 2000)

\begin{tabular}{|l|c|c|c|}
\cline { 2 - 4 } \multicolumn{1}{c|}{} & Preto & Pardo & Branco \\
\hline Tem antepassado branco & - & 80 & 59 \\
\hline Tem antepassado negro & 37 & 80 &. \\
\hline Tem antepassado índio & 28 & 48 & 44 \\
\hline
\end{tabular}

*Não incluimos amarelos ou índios porque o numero de casos foi muito pequeno para ter estimativas confiáveis. 
TABELA 2

O governo tem obrigação especial de ajudar os negros a melhorarem sua condição de vida?

A. Estado do Rio de Janeiro, 2000, Estudo CEAP/UFF

\begin{tabular}{|l|c|c|c|}
\cline { 2 - 4 } \multicolumn{1}{c|}{$\%$} & Brancos & Negros & Total \\
\hline Tem obrigação especial & 46 & 56 & 51 \\
\hline Não deve dar tratamento especial & 54 & 44 & 49 \\
\hline Total & 100 & 100 & 100 \\
\hline Número de casos & $(488)$ & $(523)$ & $(1.011)$ \\
\hline
\end{tabular}

B. Estados Unidos, 1996, General Social Survey

\begin{tabular}{|l|c|c|c|}
\cline { 2 - 4 } \multicolumn{1}{c|}{$\%$} & Brancos & Negros & Total \\
\hline Governo deveria ajudar & 12 & 47 & 17 \\
\hline Concorda com as duas posições & 28 & 36 & 29 \\
\hline Não deve dar tratamento especial & 60 & 17 & 54 \\
\hline Total & 100 & 100 & 100 \\
\hline Número de casos & $(1.516)$ & $(273)$ & $(1.789)$ \\
\hline
\end{tabular}

Como se observa na Tabela 2, 56\% dos negros brasileiros acham que o governo tem obrigação especial de ajudar os negros, enquanto $54 \%$ dos brancos consideram que não tem. Isto confirma os resultados esperados, em que os negros apoiam a intervenção do governo para ajudar a população negra e a maioria dos brancos é contrária. Entretanto, são pequenas as diferenças entre os que concordam e os que discordam nos dois contextos. Os resultados para os EUA vão na mesma direção; no entanto, a magnitude das diferenças é muito maior. Enquanto $47 \%$ dos negros concordam que o governo deve ajudar, $60 \%$ dos brancos dizem que não. Os dados entre os dois países não são estreitamente comparáveis, posto que há um grupo de indecisos entre os norte-americanos. De qualquer forma, fica claro que as opiniões entre negros e brancos divergem mais nesta matéria nos Estados Unidos do que no Brasil. De fato, entre os quatro grupos - negros e brancos nos dois países - foram os norte-americanos brancos os únicos que se posicionaram fortemente contrários à ajuda governamental para os negros.

A segunda pergunta analisada foi sobre quotas de negros para entrar na universidade. A pergunta para o Rio de Janeiro foi, "No Brasil há muito poucos negros estudando nas universidades. Algumas pessoas acham que para mudar essa situação o Governo deveria reservar vagas para os negros nas universidades públicas. Outras pessoas acham que a reserva de vagas para os negros pelo Governo colocaria outras pessoas em desvantagem. O(a) Sr(a) acha que o Governo deve reservar vagas para os negros nas universidades públicas ou o Governo não deve reservar vagas para os negros 
nas universidades públicas." As possibilidades de respostas foram: "o Governo deve reservar vagas para os negros nas universidades públicas" e "o Governo não deve reservar vagas para os negros nas universidades públicas." A pergunta nos Estados Unidos foi "Algumas pessoas dizem que por causa de discriminação no passado, se deveria dar preferência aos negros qualificados no ingresso à universidade. Outros dizem que isto é inçorreto porque discrimina os brancos. Como você se sente, é a favor ou contra a preferência aos negros no ingresso à universidade." A terminologia usada é distinta entre os dois países, no caso brasileiro foi utilizado "reservar vagas" e referência a "bons empregos"; no caso norte-americano, foi utilizado "preferências para negros qualificados".

\section{TABELA 3}

\section{Políticas para Negros na Universidade}

A. Reservar vagas para negros na universidade, Estado do Rio de Janeiro, 2000, Pesquisa CEAP/UFF

\begin{tabular}{|l|c|c|c|}
\cline { 2 - 4 } \multicolumn{1}{c|}{} & Brancos & Negros & Total \\
\hline Deve reservar vagas & 48 & 62 & 55 \\
\hline Não deve reservar vagas & 52 & 38 & 45 \\
\hline Total & 100 & 100 & 100 \\
\hline Número de casos & $(191)$ & $(213)$ & $(404)$ \\
\hline
\end{tabular}

B. Preferências para negros na universidade, Estados Unidos, 1991, Race and Politics Survey

\begin{tabular}{|l|c|c|c|}
\cline { 2 - 4 } \multicolumn{1}{c|}{$\%$} & Brancos & Negros & Total \\
\hline Deve reservar vagas & 45 & 86 & 50 \\
\hline Não deve reservar vagas & 55 & 14 & 50 \\
\hline Total & 100 & 100 & 100 \\
\hline Número de casos & $(1.692)$ & $(237)$ & $(1.929)$ \\
\hline
\end{tabular}

Os resultados para o Brasil mostram que $52 \%$ dos brancos opinam que não se deve reservar vagas nas universidades, enquanto $62 \%$ dos negros são a favor da reserva de vagas. No caso dos Estados Unidos, encontra-se ainda maior polarização: 55\% dos brancos são contrários à reserva de vagas e $86 \%$ dos negros são favoráveis. Cabe mencionar que em outros questionários, em que não se encontra o termo "negros qualificados", a brecha é ainda maior. ${ }^{2}$ De qualquer forma, o grau de diferenças das opiniões entre brancos e negros é claramente maior nos Estados Unidos. Isto refletiria a chamada "Racial Divide" (Divisão Racial) desse país, onde a variável raça cria uma brecha larga de atitudes na população.

\footnotetext{
2 Por exemplo, o National Election Survey, em 1986, encontrou que somente $30 \%$ dos brancos apoiam quotas nas universidades para negros (Kinder and Sanders 1996) e o Institute for Social Research encontrou que somente 26\% dos brancos apoiam quotas (Schuman et al 1997).
} 
A terceira pergunta referia-se às ações compensatórias no campo do emprego. Para o Rio de Janeiro perguntou-se sobre o grau de concordância ou discordância com respeito às vagas para negros nos bons empregos. Especificamente, perguntou-se: "Levando em conta ainda a questão da reserva de vagas, o(a) Sr(a). concorda ou discorda que se deva reservar vagas em bons empregos para trabalhadores negros, já que, em geral, eles têm empregos piores que os brancos? Muito ou Pouco?".

Nos Estados Unidos a pergunta foi “algumas pessoas dizem que por causa da discriminação no passado, negros deveriam ter preferência na contratação e promoção de empregos. Outros dizem que tal preferência discriminam os outros. Qual é sua opinião, você é a favor ou contra a preferência na contratação e promoção de empregos?" A questão para os Estados Unidos se refere, de fato, à contratação e promoção de negros. Dessa forma, a diferença entre as questões dá-se principalmente quanto aos termos "preferência" e "vagas." A primeira aponta um significado de políticas menos rígidas que vagas, dado que vagas comumente são entendidas como quotas que implicam números fixos.

\section{TABELA 4}

Negros no mercado de trabalho.

A. Reservar vagas em bons empregos para negros, Estado do Rio de Janeiro, 2000, Pesquisa CEAP/UFF.

\begin{tabular}{|l|c|c|c|}
\cline { 2 - 4 } \multicolumn{1}{c|}{$\%$} & Brancos & Negros & Total \\
\hline Concordo muito & 34 & 55 & 45 \\
\hline Concordo pouco & 14 & 11 & 12 \\
\hline Desacordo pouco & 15 & 11 & 13 \\
\hline Desacordo muito & 37 & 23 & 30 \\
\hline Total & 100 & 100 & 100 \\
\hline Número de casos & $(483)$ & $(521)$ & $(1.004)$ \\
\hline
\end{tabular}

B. Preferência por negros na ocupação e promoção de empregos, Estados Unidos, 1994, General Social Survey.

\begin{tabular}{|l|c|c|c|}
\cline { 2 - 4 } \multicolumn{1}{c|}{$\%$} & Brancos & Negros & Total \\
\hline Concorda muito & 04 & 45 & 10 \\
\hline Concorda pouco & 05 & 16 & 07 \\
\hline Desacorda pouco & 20 & 17 & 26 \\
\hline Desacorda muito & 71 & 22 & 57 \\
\hline Total & 100 & 100 & 100 \\
\hline Número de casos & $(1.149)$ & $(180)$ & $(1.329)$ \\
\hline
\end{tabular}


A tendência no caso brasileiro é de que a maioria dos negros apoia as vagas e, no caso norteamericano, apóia as preferências no mercado de trabalho, enquanto que a maioria dos brancos é contrária nos dois países. Novamente, as diferenças raciais são bem maiores nos Estados Unidos, onde só 9\% dos brancos concordam muito ou pouco com uma política preferencial, comparados aos $61 \%$ dos negros. No Brasil, quase a metade dos brancos (48\%) concorda com vagas em bons empregos, comparado com $66 \%$ dos negros. Assumindo que a oposição às vagas tenderia ser mais forte que a oposição à preferência, a porcentagem de brancos brasileiros favoráveis à preferência seria ainda maior que seu apoio às vagas. Concluindo, os brancos norteamericanos discordam claramente de políticas preferenciais de emprego para negros, enquanto os brancos brasileiros tendem a se dividir em suas opiniões.

Finalmente, enfatizamos a importância de diferenciar brancos e negros por status socioeconômico ou nível educacional no Brasil, pois encontramos que muitas das diferenças raciais são sensíveis a este fator. Usando as três perguntas anteriores, tratamos de demonstrar as diferenças raciais por nível de escolaridade na Tabela 5. As diferenças por níveis de escolaridade são maiores que as diferenças raciais. Em todos os casos, a porcentagem de negros que apoiam a intervenção do governo em favor de vagas e bons empregos para os nregros é maior que para brancos. Entretanto, observa-se que nos dois níveis de escolaridade mais baixos, brancos e negros apoiam tais políticas, enquanto nos níveis mais altos, a maioria dos brancos e os negros discordam das mesmas. Dessa forma, nossa hipótese inicial de que a maioria dos negros apoiaria as políticas anti-racistas de intervenção governamental não foi sustentada pelos negros com maior escolaridade e foi sustentada fortemente pelos brancos de baixa escolaridade. Para os negros com nível escolar universitário, as porcentagens de apoio ao princípio de obrigação governamental; apoio à reserva de vagas na universidade e apoio à reserva de vagas em bons empregos são, respectivamente, 35\%, 36\% e 24\%. Cabe notar que só 3\% dos negros entrevistados têm curso universitário completo comparado aos $10 \%$ dos brancos. 
TABELA 5

Porcentagem de pessoas que concordam com Políticas Anti-Racistas por Raça e Nível de Escolaridade, (Rio de Janeiro, 2000).

\begin{tabular}{|l|c|c|c|c|c|}
\cline { 2 - 6 } \multicolumn{1}{c|}{} & \multicolumn{5}{c|}{ Nível de escolaridade } \\
\cline { 2 - 6 } \multicolumn{1}{c|}{$\begin{array}{c}\text { Primário } \\
\text { incompleto }\end{array}$} & $\begin{array}{c}\text { Primário } \\
\text { completo }\end{array}$ & $\begin{array}{c}2^{\circ} \cdot \text { grau } \\
\text { incompleto }\end{array}$ & $\begin{array}{c}2^{\circ} \text {. grau } \\
\text { completo }\end{array}$ & $\begin{array}{c}\text { Superior } \\
\text { completo }\end{array}$ \\
\hline $\begin{array}{l}\text { Governo tem obrigação } \\
\text { especial }\end{array}$ & & & & & \\
\hline Brancos & 68 & 54 & 37 & 37 & 17 \\
\hline Negros & 75 & 60 & 51 & 39 & 35 \\
\hline Diferença & 07 & 06 & 14 & 02 & 18 \\
\hline $\begin{array}{l}\text { Reserva Vagas } \\
\text { Universidade }\end{array}$ & & & & & \\
\hline Brancos & 78 & 69 & 38 & 35 & 04 \\
\hline Negros & 84 & 78 & 52 & 39 & 36 \\
\hline Diferença & 06 & 09 & 14 & 4 & 32 \\
\hline $\begin{array}{l}\text { Reserva Vagas Bons } \\
\text { Empregos }\end{array}$ & & & & & \\
\hline Brancos & 75 & 59 & 44 & 35 & 06 \\
\hline Negros & 86 & 76 & 53 & 50 & 24 \\
\hline Diferença & 11 & 17 & 09 & 15 & 18 \\
\hline
\end{tabular}

Cabe observar ainda que as diferenças entre negros e brancos quanto ao apoio às políticas compensatórias são maiores entre as pessoas que concluíram o ensino universitário. Entre eles, $18 \%$ dos negros dizem que o governo tem obrigação especial, e 32\% dos negros concordam com vagas para negros na universidade. No caso de vagas nos bons empregos, a diferença é de $18 \%$. A maior diferença entre negros e brancos ocorre no nível de escolaridade mais elevado e diz respeito a uma oposição, especialmente forte, dos brancos à intervenção do governo para ajudar negros e à reserva de vagas para promoção de negros. Só 17\% dos brancos de nível superior são a favor de uma intervenção governamental, apenas $4 \%$ apoiam quotas para a universidade, e $6 \%$ apoiam quotas para bons empregos. ${ }^{3}$

\section{Conclusões}

Como era esperado, a maioria de negros tende a apoiar políticas compensatórias para negros, enquanto os brancos tendem a discordar. Em termos

\footnotetext{
${ }^{3}$ Nossas conclusões para pessoas de alto nivel de escolaridade são tentativas, dado que o pequeno número de casos implica uma grande margem de erro. O número de casos para pessoas com curso superior completo varia de 11 a 17 para negros e 25 a 47 para brancos, dependendo da pergunta.
} 
comparativos, o que mais se destaca em nossa análise é a relativa simetria das respostas entre brancos e negros no Brasil, comparativamente aos Estados Unidos, onde as respostas entre brancos e negros são praticamente opostas. Uma grande maioria dos brancos norte-americanos é contrária a tais políticas, e esse sentimento tem impedido os avanços na área dos direitos civis, bem como derrubado muitos programas de ação afirmativa nesse país. A forte oposição branca é particularmente problemática para os negros norte-americanos que representam pouco mais de 10\% da população, criando o que Tocqueville chamou, há mais de um século atrás, de a Tirania da Maioria.

A divisão racial nas atitudes de brancos e negros nos Estados Unidos tem sido uma característica marcante desse país (Schuman et al 1997) e o mundo deuse conta no julgamento do famoso futebolista norte-americano, O.J. Simpson. Nesse caso, houve percepções opostas entre negros e brancos sobre a culpabilidade de O.J. Simpson em assassinar sua ex-companheira que era branca.

Concluindo, poderíamos dizer que, no Brasil, apesar de uma resistência da elite branca em apoiar políticas compensatórias, há uma conjuntura favorável a uma discussão maior sobre estas políticas. Consideramos o fato de que esses programas têm no apoio de quase metade dos brancos e na maioria dos negros um bom ponto de partida para começar uma discussão mais ampla sobre o tema. Um Brasil democrático não pode evitar uma discussão franca da qual façam parte setores em desvantagem, particularmente a população considerada negra que representa quase metade da população total. Trata-se de um momento histórico importante para criar políticas anti-racistas de consenso.

\section{BIBLIOGRAFIA}

PENA, Sérgio D.J., SILVA, , Denise R. Carvalho, SILVA, Juliana Alves, PRADO, Vania F. \& SANTOS, Fabrício R. (2000) Retrato Molecular do Brasil. Ciência Hoje. Abril.

KINDER, Donald R. \& SANDERS, Lynn M. (1996) Divided by Color: Racial Politics and Democratic Ideas. Chicago, The University of Chicago Press.

OMI, Michael \& WINANT, Howard. (1994). Racial Formation in the United States: From the 1960s to the 1980s. $2^{\text {nd }}$ ed. New York, Routledge.

SCHUMAN, Howard, STEEH, Charlotte, BOBO, Lawrence \& KRYSAN, Maria. (1997) Racial Attitudes in America: Trends and Interpretations. Cambridge, Harvard University Press.

TWINE, Francis Windance. (1998) Racism in a Racial Democracy: The Maintenance of White Supremacy. New Brunswick, Rutgers University Press.

Recebido para publicação em março de 2002. 